\title{
Harnessing $\alpha$-Emitting Radionuclides for Therapy: Radiolabeling Method Review
}

\author{
Hua Yang ${ }^{1,2}$, Justin J. Wilson ${ }^{3}$, Chris Orvig ${ }^{4}$, Yawen $\mathrm{Li}^{5}$, D. Scott Wilbur ${ }^{5}$, Caterina F. Ramogida ${ }^{1,2}$, Valery Radchenko ${ }^{1,6}$, \\ and Paul Schaffer ${ }^{1,2,7}$ \\ ${ }^{1}$ Life Sciences Division, TRIUMF, Vancouver, British Columbia, Canada; ${ }^{2}$ Department of Chemistry, Simon Fraser University, Burnaby, \\ British Columbia, Canada; ${ }^{3}$ Chemistry and Chemical Biology, Cornell University, Ithaca, New York; ${ }^{4}$ Medicinal Inorganic Chemistry \\ Group, Department of Chemistry, University of British Columbia, Vancouver, British Columbia, Canada; ${ }^{5}$ Department of Radiation \\ Oncology, University of Washington, Seattle, Washington; ${ }^{6}$ Department of Chemistry, University of British Columbia, Vancouver, \\ British Columbia, Canada; and ${ }^{7}$ Department of Radiology, University of British Columbia, Vancouver, British Columbia, Canada
}

Targeted $\alpha$-therapy (TAT) is an emerging powerful tool treating latestage cancers for which therapeutic options are limited. At the core of TAT are targeted radiopharmaceuticals, where isotopes are paired with targeting vectors to enable tissue- or cell-specific delivery of $\alpha$-emitters. DOTA (1,4,7,10-tetraazacyclododecane-1,4,7,10-tetraacetic acid) and DTPA (diethylenetriamine pentaacetic acid) are commonly used to chelate metallic radionuclides but have limitations. Significant efforts are underway to develop effective stable chelators for $\alpha$-emitters and are at various stages of development and community adoption. Isotopes such as ${ }^{149} \mathrm{~Tb},{ }^{212 / 213} \mathrm{Bi},{ }^{212} \mathrm{~Pb}$ (for ${ }^{212} \mathrm{Bi}$ ), ${ }^{225} \mathrm{Ac}$, and ${ }^{226 / 227} \mathrm{Th}$ have found suitable chelators, although further studies, especially in vivo studies, are required. For others, including ${ }^{223} \mathrm{Ra},{ }^{230} \mathrm{U}$, and, arguably ${ }^{211} \mathrm{At}$, the ideal chemistry remains elusive. This review summarizes the methods reported to date for the incorporation of ${ }^{149} \mathrm{~Tb},{ }^{211} \mathrm{At},{ }^{212 / 213} \mathrm{Bi},{ }^{212} \mathrm{~Pb}$ (for ${ }^{212} \mathrm{Bi}$ ), ${ }^{223} \mathrm{Ra},{ }^{225} \mathrm{Ac},{ }^{226 / 227} \mathrm{Th}$, and ${ }^{230} \mathrm{U}$ into radiopharmaceuticals, with a focus on new discoveries and remaining challenges.

Key Words: $\alpha$-emitter; targeted $\alpha$-therapy; chelation; radiolabeling; review

J Nucl Med 2022; 63:5-13

DOI: 10.2967/jnumed.121.262687

$\mathbf{T}$ argeted radionuclide therapy has demonstrated significant therapeutic efficacy and survival benefit for some conditions, especially for late-stage disease with limited therapeutic alternatives $(1,2)$. Several isotopes, such as ${ }^{177} \mathrm{Lu},{ }^{90} \mathrm{Y},{ }^{89} \mathrm{Sr},{ }^{153} \mathrm{Sm}$, and ${ }^{131} \mathrm{I}$, are in clinical use for treatment of neuroendocrine tumors $\left({ }^{177} \mathrm{Lu}-\right.$ DOTATATE [Lutathera; Advanced Accelerator Applications]),

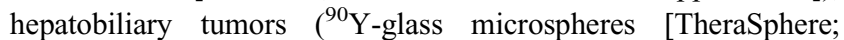
Boston Scientific]), bone metastases $\left({ }^{89} \mathrm{Sr}\right.$-chloride [Metastron; GE Healthcare] and ${ }^{153} \mathrm{Sm}$-lexidronam [Quadramet; Lantheus Medical Imaging]), and non-Hodgkin lymphoma (tositumomab and ${ }^{131}$ I-tosutumomab [Bexxar; GlaxoSmithKline]), respectively. Most isotopes used for targeted radionuclide therapy are $\beta$-emitters, with ${ }^{223} \mathrm{Ra}$ ([ $\left.{ }^{223} \mathrm{Ra}\right] \mathrm{RaCl}_{2}$, Xofigo; Bayer) being the only Food and Drug Administration-approved $\alpha$-emitter to date for the

Received Jun. 11, 2021; revision accepted Aug. 5, 2021.

For correspondence or reprints, contact Hua Yang (hyang@triumf.ca). Published online Sep. 9, 2021.

COPYRIGHT (C) 2022 by the Society of Nuclear Medicine and Molecular Imaging. treatment of patients with metastatic castration-resistant prostate cancer with symptomatic bone metastases and no known visceral metastatic disease. $\alpha$-emitters have much higher linear energy transfer (energy deposition per unit pathlength) than do $\beta$-emitters $(\sim 100 \mathrm{keV} / \mu \mathrm{m}$ vs. $1-2 \mathrm{keV} / \mu \mathrm{m})$ and generate substantially more free radicals and lethal DNA double-strand breaks $(3,4)$.

When delivered via tumor-specific targeting vectors, the short range of $\alpha$-particles $(40-100 \mu \mathrm{m})$ enables highly selective targeting of cancers, including micrometastases, while potentially sparing surrounding healthy tissues. The cytotoxicity of $\alpha$-emitters is also independent of cell cycle or oxygen concentration $(5,6)$, providing an advantage for treating hypoxic, often radiation-resistant tumors (7).

Targeted $\alpha$-therapy (TAT) has been fast-tracked by the Food and Drug Administration approval of $\left[{ }^{223} \mathrm{Ra}^{2} \mathrm{RaCl}_{2}\right.$ for the treatment of bone metastases of metastatic castration-resistant prostate cancer, and ${ }^{225}$ Ac-PSMA617, which is in pilot trials to treat metastatic castration-resistant prostate cancer, has shown remarkable clinical effectiveness $(8,9)$.

Few $\alpha$-emitting radionuclides suitable for clinical use are available, considering half-life, decay mode, and availability. Isotopes with potential medical applications and their properties are listed in Table 1 . With the exception of $\left[{ }^{223} \mathrm{Ra}\right] \mathrm{RaCl}_{2}$, TAT typically comprises an isotope, a targeting vector (e.g., small molecule, peptide, antibody, or engineered antibody), and a chelator that can form a stable complex and carry the isotope to deliver high-linear-energytransfer radiation directly to cancer cells and the tumor microenvironment. An ideal chelator exhibits fast metal-complexation kinetics, selectivity for the radionuclide (because of inevitable metal impurities), high thermodynamic stability, high in vivo stability, and the ability to bind an imaging isotope for theranostics applications. Many of the isotopes in this review decay through multiple daughter products, each with its own unique coordination chemistry. The issue of daughter recoil and coordination presents a unique set of physics and chemistry challenges that are beyond the scope of this review (10).

DOTA (1,4,7,10-tetraazacyclododecane-1,4,7,10-tetraacetic acid) has been a standard chelator for radiometals and is still useful for coordinating $\mathrm{Ac}, \mathrm{Bi}, \mathrm{Tb}, \mathrm{Th}$, and $\mathrm{Pb}$; however, issues remain with this chelate, including decreased thermodynamic stability toward large metal ions and slow chelation kinetics. High ligand concentration, which reduces the molar activity, and heating are required, which may compromise some targeting vectors. Sensitivity to metal 
TABLE 1

Isotopes for TAT

\begin{tabular}{lcccccc}
\hline Isotope & Half-life & Common ion & lonic radius $(\AA)$ & $\begin{array}{c}\text { Common } \\
\text { coordination number }\end{array}$ & Hard/soft & pKa (aqueous) \\
\hline${ }^{149} \mathrm{~Tb}$ & $4.1 \mathrm{~h}$ & $\mathrm{~Tb}^{3+}$ & 1.04 & $8-9$ & Hard & 7.9 \\
${ }^{211} \mathrm{At}$ & $7.2 \mathrm{~h}$ & $\mathrm{At}^{+}, \mathrm{AtO}^{+}$ & - & - & - & - \\
${ }^{212} \mathrm{Bi}$ & $60.6 \mathrm{~min}$ & $\mathrm{Bi}^{3+}$ & 1.17 & 8 & Intermediate & 1.1 \\
${ }^{213} \mathrm{Bi}$ & $45.6 \mathrm{~min}$ & $\mathrm{Bi}^{3+}$ & 1.17 & 8 & Intermediate & 1.1 \\
${ }^{212} \mathrm{~Pb}\left(\mathrm{for}{ }^{212} \mathrm{Bi}\right)$ & $10.6 \mathrm{~h}$ & $\mathrm{~Pb}^{2+}$ & 1.43 & 8 & Intermediate & 0.9 \\
${ }^{223} \mathrm{Ra}$ & $11.4 \mathrm{~d}$ & $\mathrm{Ra}^{2+}$ & 1.48 & $8-12$ & Hard & 3.1 \\
${ }^{225} \mathrm{Ac}$ & $9.9 \mathrm{~d}$ & $\mathrm{Ac}^{3+}$ & 1.12 & $9-10$ & Hard & 9.4 \\
${ }^{226} \mathrm{Th}$ & $30.7 \mathrm{~min}$ & $\mathrm{Th}^{4+}$ & 1.05 & $>8$ & Hard & 3.2 \\
${ }^{227} \mathrm{Th}$ & $18.7 \mathrm{~d}$ & $\mathrm{Th}^{4+}$ & 1.05 & $>8$ & Hard & 3.2 \\
${ }^{230} \mathrm{U}$ & $20.8 \mathrm{~d}$ & {$\left[\mathrm{UO}_{2}\right]^{2+}$} & - & 6 & Hard & 4.2 \\
\hline
\end{tabular}

impurities is another shortcoming. Thus, much work is required to develop suitable chelators for $\alpha$-emitters, particularly Ra, U, and arguably At. The need for novel, suitable labeling methods remains unmet for the rapidly expanding field of TAT. In this review, we will discuss the current state of the art of labeling method development for medically relevant $\alpha$-emitters and their applications in TAT.

\section{CHEMISTRY TO LABEL $\alpha$-EMITTERS}

${ }^{149} \mathrm{~Tb}$

Cyclen-based chelators, diethylenetriamine pentaacetic acid (DTPA), and dipicolinic acids are among the many chelators reported to complex $\mathrm{Tb}^{3+}(11,12)$. Chelators that form stable complexes with $\mathrm{Lu}^{3+}$ may also do the same with $\mathrm{Tb}^{3+}$, although binding may be weaker, as $\mathrm{Tb}^{3+}$ has a larger atomic radius.

Medical applications of $\mathrm{Tb}$ isotopes are at an early stage; they bind DOTA effectively, and also $(S, S)$-cyclohexane-1,2-diaminepentaacetic acid (CHX-A"-DTPA), preferentially for antibody labeling because of the fast kinetics and ambient temperature metal incorporation. PET imaging with ${ }^{149} \mathrm{~Tb}$-DOTANOC has shown excellent tumor visualization (13), ${ }^{149}$ Tb-DOTA-folate (cm09) was found to delay tumor growth in a dose-dependent manner (14), and ${ }^{149} \mathrm{~Tb}-\mathrm{CHX}-\mathrm{A}^{\prime \prime}$-DTPA-rituximab (anti-CD-20) demonstrated tumor-free survival in $89 \%$ of the mice treated $2 \mathrm{~d}$ after tumor inoculation (15).

To date, only DOTA and CHX-A"-DTPA have been studied with radio- $\mathrm{Tb}$ isotopes, and reports on their preclinical applications are limited (Fig. 1); additional Tb chelates would yield more ideal candidates with improved kinetics or stability. The intense luminescent properties of various $\mathrm{Tb}$ complexes may be leveraged for use in optical/radio multimodality imaging.

\section{NOTEWORTHY}

- $\alpha$-emitting radionuclides may require new methods to be efficiently incorporated and stably delivered in vivo.

New chemistry (chelators or astination methods) is quickly emerging, although more in-depth investigation of the applications and limitations are required.

- For ${ }^{223} \mathrm{Ra}$ and ${ }^{230} \mathrm{U}$, stable chelators are yet to be discovered.
${ }^{211}$ At

Comprehensive reviews summarizing organic and inorganic chemical methods for producing radioastatinated compounds have been published (16-18). Briefly here, isotopes of At have relatively short half-lives (the longest is $8.1 \mathrm{~h}$, none are stable), and radioiodine is commonly used as a surrogate when studying At chemistry, despite a divergence in reactivity with different labeling reagents and in vivo stability of the products formed. Although At has metallic character, to date no chelating ligand evaluated provides an ${ }^{211}$ At complex with enough in vivo stability for TAT applications (16-18). An exception may be a rhodium(III) astatide complex stabilized by a macrocyclic crown thioether $\left(16 \mathrm{aneS}_{4}\right.$-diol) (19). Differences in the biodistribution of $\mathrm{Rh}\left[16 \mathrm{aneS}_{4} \text {-diol }\right]^{131} \mathrm{I}$ and $\mathrm{Rh}\left[16 \mathrm{aneS}_{4}\right.$-diol] ${ }^{211}$ At suggest some deastatination of the latter, but the in vivo stability may be potentially useful (19). How stable the ${ }^{211}$ At label must be before it can be useful for patient treatment has not been established.

A few At labeling methods use a nonactivated aryl-At bonding approach (16-18), with the most widely used method involving organometallic compounds such as $\mathrm{N}$-succinimidyl 3-(tri-alkylstannyl)benzoate, compound 2 , in electrophilic substitution reactions (Fig. 2). This approach was used in many preclinical studies and more recently in two phase I clinical trials for treating brain or ovarian cancer $(20,21)$. In these trials, the ${ }^{211}$ At-labeled radiopharmaceutical was prepared using a 2-step labeling approach. A 1-step labeling approach has been demonstrated by the Gothenburg team wherein the tri-alkylstannyl benzoate is conjugated before radiolabeling (22).

Nonactivated arylboronic acid derivatives were shown to react rapidly with electrophilic At species. More recently, nucleophilic substitution reactions using aryl boronic acids/esters have been shown to provide highly efficient ${ }^{211}$ At-labeling. A series of ${ }^{211}$ Atlabeled compounds was prepared using boronic ester precursors and a $\mathrm{Cu}$ catalyst, including the ${ }^{211}$ At-labeled poly(adenosine diphosphate-ribose)polymerase-1 inhibitor [ $\left.{ }^{211} \mathrm{At}\right] \mathrm{MM} 4$ (compound 3a, Fig. 2), which exhibited a biodistribution profile similar to that of its ${ }^{18} \mathrm{~F}$ and ${ }^{125} \mathrm{I}$ analogs and could potentially be useful for TAT applications $(23,24)$. Cu-catalyzed astatination and radioiodination reactions using arylboronic acids can be conducted in aqueous solution at ambient temperature and thus are suitable for monoclonal antibody (mAb) labeling. Cu-catalyzed astatination and 


\begin{tabular}{|l|l|l|l|l|l|}
\hline Radiometal & Ligand & Bioconjugates & $\begin{array}{l}\text { Labeling } \\
\text { conditions }\end{array}$ & $\begin{array}{l}\text { In vivo } \\
\text { stability }\end{array}$ & Ref. \\
\hline${ }^{149} \mathrm{~Tb}$ & $\begin{array}{l}\text { DOTANOC } \\
\text { DOTA-folate } \\
\text { (cm09) }\end{array}$ & $\begin{array}{l}95^{\circ} \mathrm{C}, 15 \mathrm{~min}, \\
\alpha-\mathrm{HIBA} \mathrm{pH} 4.7\end{array}$ & Stable & $(13,14)$ \\
& & & & & \\
& & & & & \\
\end{tabular}

FIGURE 1. Chelates for ${ }^{149} \mathrm{~Tb} . \mathrm{RT}=$ room temperature.

radioiodination of arylboronic acid-conjugated mAbs (compound 4, Fig. 2), such as anti-CD138 antibody, 9E7.4 (25), have been reported.

Aryliodonium salts can also be used for mAb conjugate labeling via nucleophilic substitution. For example, asymmetric aryliodonium salts with one of the aryl rings bearing an $\mathrm{N}$-hydroxysuccinimidyl ester (compounds 5a-5c, Fig. 2) were conjugated to anti-CD138 $\mathrm{mAb}$ for astatination and radioiodination studies (25). Striking differences were observed between radioiodination and astatination reactions in regioselectivity and in reaction conditions required to obtain optimal radiochemical yield; the astatination reaction using aryliodonium salts is more efficient than the radioiodination.

Another ${ }^{211}$ At-labeling reagent that has been used in preclinical and clinical studies is the isothiocyanatophenyl-closo-decaborate(2-) (B10) boron cage molecule (compound 6, Fig. 2) (25). The ${ }^{211}$ Atlabeled $\mathrm{B} 10$-conjugated anti-CD45 mAb BC8 is currently being evaluated in 2 phase I/II trials for hematopoietic cell transplantation in patients with leukemia, myelodysplastic syndrome, and nonmalignant diseases. The aromatic B10 moiety provides high ${ }^{211}$ At labeling efficiency $(75 \%-90 \%$ radiochemical yield, 1 min) with high in vivo stability. New boron cage ${ }^{211}$ At-labeling reagents to potentially stabilize ${ }^{211}$ At in a higher oxidation state, +3 or +5 , are being evaluated for improved tissue distribution and more favorable pharmacokinetic properties (25).

Overall, ${ }^{211}$ At is a highly attractive radionuclide for TAT applications. To date, electrophilic substitution on unactivated aromatic rings is the most widely used astatination method for TAT preclinical and clinical radiopharmaceutical synthesis. Other recent studies demonstrate the potential of nucleophilic substitution reactions for astatination of small molecules and mAbs $(23,24)$. In addition to the aryl-At bonding approach, boron-At bonding provides an alternative astatination strategy. Other astatination strategies that involve the use of chelation chemistry, nanoparticles, and others have been explored but have yet to show potential for use in humans (26).

\section{${ }^{212 / 213} \mathrm{Bi}$}

DOTA and CHX-A"-DTPA are frequently used for Bi labeling, but neither chelate is a good match for $\mathrm{Bi}^{3+}$. Bi-DOTA or BiCHX-A"-DTPA complexes are not sufficiently stable in human plasma (85\% DOTA, 76\% CHX-A"-DTPA, 2 h) (27). Nonetheless, their efficacy was tested successfully in vivo for antibodies and peptides, with CHX-A"-DTPA used primarily for antibody conjugates and DOTA for peptides (Fig. 3). Radiopharmaceuticals in clinical studies include ${ }^{213} \mathrm{Bi}-\mathrm{HuM} 195,{ }^{213} \mathrm{Bi}$-anti-CD20$\mathrm{mAb},{ }^{213} \mathrm{Bi}$-anti-EGFR-mAb, ${ }^{213} \mathrm{Bi}$-anti-MCSP-mAb (9.2.27), ${ }^{213} \mathrm{Bi}$-DOTA-substance $\mathrm{P}$, and ${ }^{213} \mathrm{Bi}$-DOTATOC. The reader is directed toward another recent review for additional information on ${ }^{213} \mathrm{Bi}$ radiopharmaceuticals $(8)$.

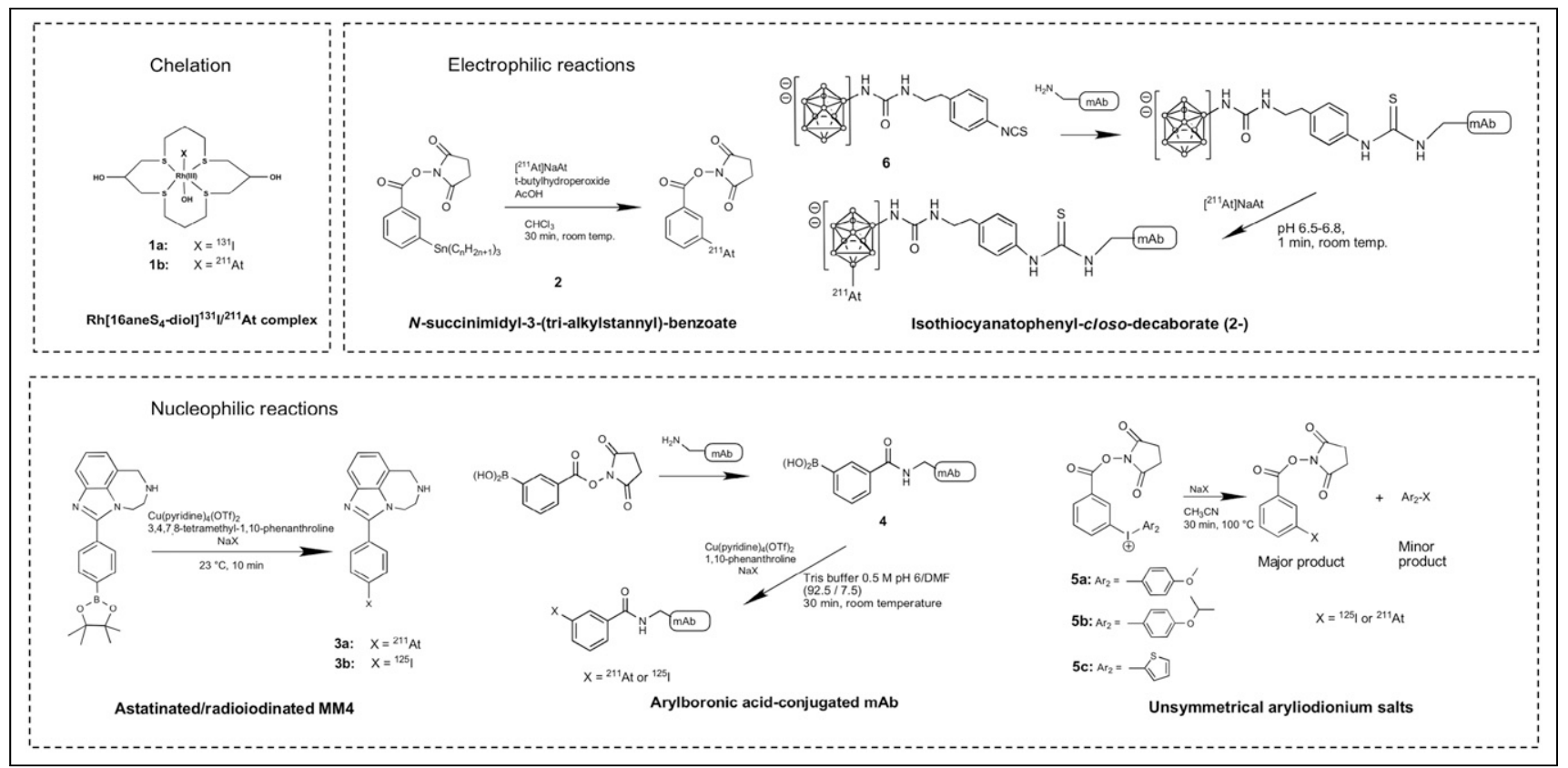

FIGURE 2. ${ }^{211} \mathrm{At}$ labeling methods. DMF = dimethylformamide; $\left.\mathrm{NaX}=\left[{ }^{125}\right]\right] \mathrm{Nal}$ or $\left[{ }^{211} \mathrm{At}\right] \mathrm{NaAt}$. 


\begin{tabular}{|c|c|c|c|c|c|}
\hline Radiometal & Ligand & Bioconjugates & $\begin{array}{l}\text { Labeling } \\
\text { conditions }\end{array}$ & $\begin{array}{l}\text { In vivo } \\
\text { stability }\end{array}$ & Ref. \\
\hline \multirow[t]{6}{*}{${ }^{213} \mathrm{Bi}$} & DOTA (see Figure 2) & $\begin{array}{l}\text { DOTATOC, } \\
\text { Substance P }\end{array}$ & $\begin{array}{l}95^{\circ} \mathrm{C}, 5 \mathrm{~min}, \\
\text { TRIS buffer }\end{array}$ & Stable & (8) \\
\hline & CHX-A"-DTPA (see Figure 2) & $\begin{array}{l}\text { lituzumab, anti- } \\
\text { CD20-mAb, anti- } \\
\text { EGFR-mAb, anti- } \\
\text { MCSP-mAb } \\
(9.2 .27) \text {, }\end{array}$ & $\begin{array}{l}\mathrm{RT} \text { or } 80^{\circ} \mathrm{C}, 5 \\
\min , \mathrm{NH}_{4} \mathrm{OAC} \\
\mathrm{pH} 5\end{array}$ & Stable & (8) \\
\hline & $\mathrm{L}^{\mathrm{Py}}$ & $\mathrm{N} / \mathrm{A}$ & $\begin{array}{l}\mathrm{RT}, 30 \mathrm{~min}, \\
\mathrm{NH}_{4} \mathrm{OAc} \mathrm{pH} 5\end{array}$ & $\mathrm{~N} / \mathrm{A}$ & (28) \\
\hline & DOTP (DOTMP) & N/A & $\begin{array}{l}\text { RT, } 5 \text { min, } \\
\text { NaOAc pH } 5\end{array}$ & N/A & $(27)$ \\
\hline & 3p-C-NETA & Trastuzumab & $\begin{array}{l}37^{\circ} \mathrm{C} 30 \mathrm{~min}, \\
\mathrm{NaOAcpH} 5.5\end{array}$ & Stable & (29) \\
\hline & $\begin{array}{r}\text { 3p-C-DEPA } \\
\text { HOOC }\end{array}$ & Trastuzumab & $\begin{array}{l}\text { RT, } 1 \text { min, } \\
\text { NaOAc pH } 5.5\end{array}$ & Stable & (30) \\
\hline
\end{tabular}

FIGURE 3. ${ }^{212 / 213} \mathrm{Bi}$ chelators. $\mathrm{N} / \mathrm{A}=$ not applicable; $\mathrm{RT}=$ room temperature.

help to improve the radiochemical yields and molar activity of potential radiopharmaceuticals. Additional in vivo studies are required to evaluate stability and demonstrate suitability for TAT. There also remains potential for further development of $S$-donor chelates, informed by meso2,3-dimercaptosuccinic and 2,3-dimercaptopropane-1-sulfonic acid, which were used for chelation therapy to prevent $\mathrm{Bi}$ overdose in humans (31).

\section{${ }^{212} \mathrm{~Pb}$}

Although not an $\alpha$-emitter itself, ${ }^{212} \mathrm{~Pb}$ is used as an internal generator for ${ }^{212} \mathrm{Bi}$. DOTA was one of the first chelators studied with ${ }^{212} \mathrm{~Pb}$ (Fig. 4). Although data suggest favorable kinetic stability of $\mathrm{Pb}$-DOTA complexes (32), release of $\mathrm{Pb}$ in vivo in the acidic tumor environment was reported in some cases and may prove to be a source of toxicity upon internalization and metabolic processing (33).

In a pretargeting approach where ${ }^{212} \mathrm{~Pb}$ DOTA-biotin was injected into mice preinoculated with streptavidin-NR-LU-10 mAb, despite the elevated dose to kidneys from free ${ }^{212} \mathrm{Bi}$, the biodistribution relative to the ${ }^{203} \mathrm{~Pb}$ counterpart was identical for all other organs, indicating little migration of ${ }^{212} \mathrm{Bi}$ once in tissue (34). ${ }^{212} \mathrm{~Pb}$-DOTA-Re $\left(\operatorname{Arg}^{11}\right)$ $\mathrm{CCMSH}$, a melanoma-targeting peptide, was evaluated in B16/F1 xenografts (35) and provided measurable therapeutic outcomes. ${ }^{212} \mathrm{~Pb}$-DOTA-103A mAb was studied for treating Rauscher leukemia virus

The nitrogen-rich cyclen-pyridine ligand $\mathrm{L}^{\mathrm{py}}$ and analogs are reported to form highly stable complexes with ${ }^{213 / 207} \mathrm{Bi}$ at room temperature (28). $\mathrm{L}^{\mathrm{py}}$ showed selectivity toward $\mathrm{Bi}^{3+}$ over $\mathrm{Ac}^{3+}$ and showed resistance to transmetalation when challenged with $\mathrm{Cu}^{2+}$, $\mathrm{Zn}^{2+}, \mathrm{Fe}^{2+}$, or $\mathrm{Bi}^{3+}$, but in vivo studies are not yet reported. The phosphorus-containing cyclen chelates DOTP (also named DOTMP, Fig. 3) and analogs form stable complexes with ${ }^{213} \mathrm{Bi}$ at room temperature as well, and ${ }^{213} \mathrm{Bi}$-DOTP showed higher stability in human serum at 120 min than did ${ }^{213} \mathrm{Bi}$-DOTA or ${ }^{213} \mathrm{Bi}-\mathrm{CHX}-\mathrm{A}^{\prime \prime}$-DTPA (27). ${ }^{213} \mathrm{Bi}$-DOTP accumulates primarily in bone, unlike free $\mathrm{Bi}^{3+}$, which accumulates in the kidneys.

${ }^{205 / 206} \mathrm{Bi}$ has been used to evaluate novel chelates such as $\{4-[2-$ (bis-carboxymethyl-amino)-ethyl]-7-carboxymethyl-[1,4,7]triazonan-1-yl\}-acetic acid (NETA, a NOTA derivative) and 7-[2-(bis-carboxymethyl-amino)-ethyl]-4,10-bis-carboxymethyl1,4,7, 10-tetraaza-cyclododec-1-yl-acetic acid (DEPA, a DOTA derivative), synthesized specifically to provide a larger cavity to coordinate with $\mathrm{Bi}^{3+}$. Both coordinate ${ }^{205 / 206} \mathrm{Bi}$ at low or ambient temperature with high efficiency $(29,30)$. Using a 3-carbon linker in the bifunctional chelates, ${ }^{205 / 206} \mathrm{Bi}-3 \mathrm{p}-C$-NETA- and ${ }^{205 / 206} \mathrm{Bi}-3 \mathrm{p}-$ $C$-DEPA-trastuzumab both showed effective tumor accumulation and low kidney uptake $(29,30)$.

Overall, because of the short half-life of the Bi isotopes, development of novel chelators such as $\mathrm{L}^{\mathrm{py}}$, DOTP, NETA, and DEPA, capable of rapid, ambient temperature metal incorporation, may
(RVB3) (36). Despite success in eradicating the target, all animals succumbed to bone marrow toxicity, in contrast to the lack of marrow toxicity in a similar study using ${ }^{212} \mathrm{Bi}-103 \mathrm{~A}-\mathrm{mAb}$. Given the observed susceptibility for some DOTA derivatives to be acid-labile at lower $\mathrm{pH}$, it has been postulated that ${ }^{212} \mathrm{~Pb}$ dissociation, followed by clearance from the target tissue and localization of the free $\mathrm{Pb} / \mathrm{Bi}$ in bone marrow, leads to the observed toxicity.

A more efficient and stable chelate for $\mathrm{Pb}$, TCMC (1,4,7,10-tetraaza-1,4,7,10-tetra-(2-carbamoyl methyl)-cyclododecane), has since become the standard for $\mathrm{Pb}$ labeling (37). Bifunctional 4-nitrobenzylisothiocyanate derivatives were used to generate ${ }^{203} \mathrm{~Pb}$ TCMC-CC49 (37) and ${ }^{212} \mathrm{~Pb}-\mathrm{TCMC}-$ trastuzumab (38). TCMCtrastuzumab conjugates were determined to be more stable and more efficient at metal conjugation than their DOTA counterparts. $\mathrm{Pb}$ TCMC-trastuzumab radioconjugate stability was analyzed in vitro, coupled with the demonstrated therapeutic effect and minimal toxicity of ${ }^{212} \mathrm{~Pb}$-trastuzumab in an orthotopic model of human prostate cancer cells (38). ${ }^{212} \mathrm{~Pb}$-TCMC-trastuzumab was used in a first-in-humans dose escalation clinical trial and was well tolerated (39).

In 2020, a biodistribution study of several ${ }^{203} \mathrm{~Pb}$ - and ${ }^{212} \mathrm{~Pb}$ labeled TCMC-PSMA derivatives was also reported (40). One derivative demonstrated tumor growth delay, with the kidney as the dose-limiting organ. Another PSMA ligand, [ $\left.{ }^{212} \mathrm{~Pb}\right] \mathrm{Pb}-\mathrm{NG} 001$, showed that ${ }^{212} \mathrm{~Pb}$ and ${ }^{212} \mathrm{Bi}$ colocalized during the $24-\mathrm{h}$ study 


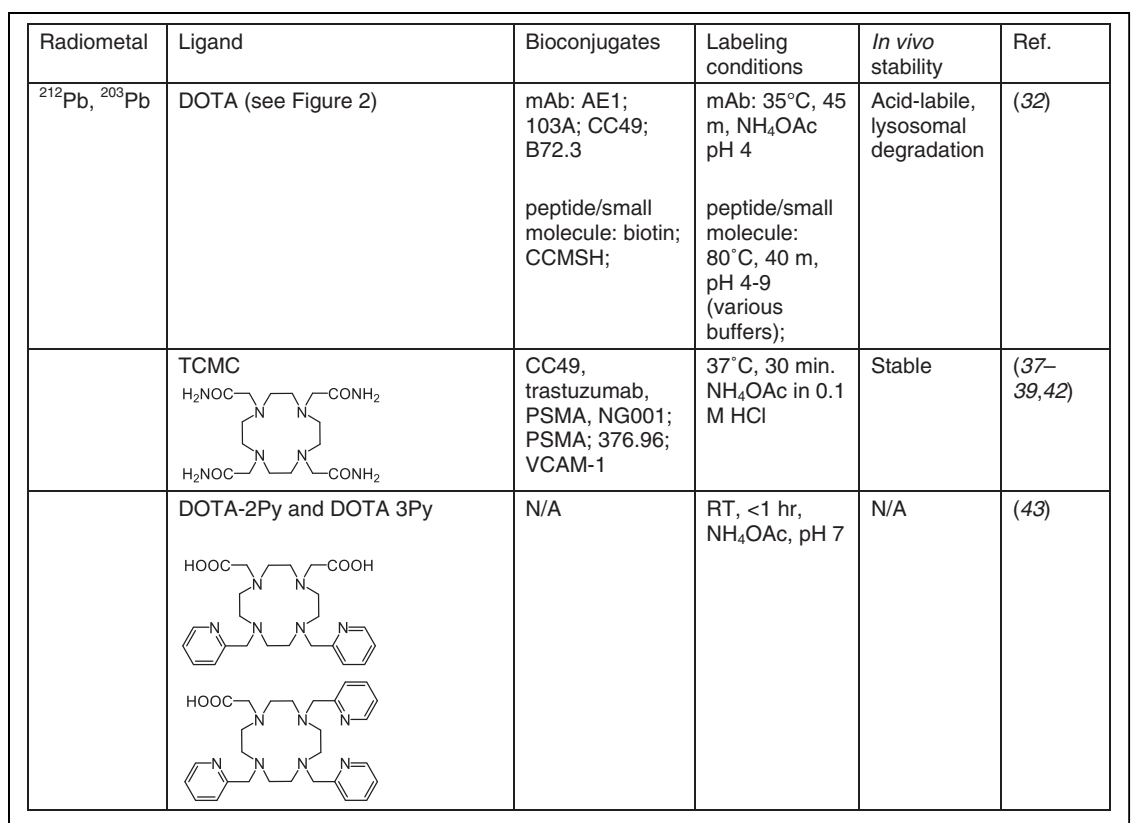

FIGURE 4. Chelators for ${ }^{212} \mathrm{~Pb} . \mathrm{N} / \mathrm{A}=$ not applicable; $\mathrm{RT}=$ room temperature.

these complexes has yet to be determined. Although calix[4]arene is effective in extracting $\mathrm{Ra}^{2+}$ in neutral $\mathrm{pH}$ solution, the stability of the complex is poor (46). A recent review examines the use of nanoparticles to immobilize ${ }^{223} \mathrm{Ra}$, including liposomes, barium sulphate, lanthanum phosphate, and hydroxyapatite, among others (26).

No suitable chelator for in vivo delivery of ${ }^{223} \mathrm{Ra}$ has been identified to date; although macropa shows promise, much work remains to develop a suitable chelate for $\mathrm{Ra}^{2+}$.

${ }^{225} \mathrm{AC}$

Most ${ }^{225}$ Ac chelates developed to date are macrocycles; DOTA remains the gold standard for Ac labeling for all clinical work. Examples inclu$\mathrm{de}^{225}$ Ac-PSMA617, ${ }^{225}$ Ac-DOTATOC, and ${ }^{225}$ Ac-DOTA-HuM195 (Fig. 6) (8). Labeling can be performed using 1-step (47) or 2-step (48) methods, with the latter being used for heat-sensitive targeting bio-

period, leading the authors to suggest that the rapid target internalization and nontarget clearance of $\left[{ }^{212} \mathrm{~Pb}\right] \mathrm{Pb}-\mathrm{NG} 001$ prevented measurable amounts of ${ }^{212} \mathrm{Bi}$ from being released from the target tissue (41). Recently, ${ }^{212} \mathrm{~Pb}$-TCMC mAb376.96 was shown to bind the B7-H3 epitope found on ovarian cancer cells, with a 2- to 3-fold increased survival in tumor-bearing mice over the control group (42).

Recently, a series of cyclen-based chelators (described as DOTA-1Py, -2Py, and -3Py) was compared with the established chelators DOTA and TCMC. All chelates incorporated ${ }^{212} \mathrm{~Pb}$ (and ${ }^{203} \mathrm{~Pb}$ ) efficiently, with radiochemical yields higher than for DOTA and lower than for TCMC (43). A separate report examined the complexation between $\mathrm{Pb}$ and calix[4]arene-1,3-crown-6, where the formation of a $1: 1-\mathrm{Pb}(\mathrm{II})$-calix complex was confirmed by ${ }^{207} \mathrm{~Pb}$ NMR (44). The phosphonic acid chelates DOTP (DOTMP) and tetra-methylenephosphonic acid (EDTMP) were labeled with $\mathrm{Pb}$ but found to have low stability in vivo (32).

Overall, ${ }^{212} \mathrm{~Pb}$ coordination chemistry appears to have emerged from a multidecade preclinical development phase and has advanced into a limited number of human clinical trials. The availability of the isotope and an imageable element-equivalent companion $\left({ }^{203} \mathrm{~Pb}\right)$, coupled with extensive development of key chelators (i.e., TCMC), suggests an exciting future for this isotope.

${ }^{223} \mathbf{R a}$

So far, the only ${ }^{223} \mathrm{Ra}^{2+}$ chelator with demonstrated in vivo stability is macropa, manifesting in low bone uptake of $\left[{ }^{223} \mathrm{Ra}\right]$ [Ra(macropa- $\beta$-alanine)] (Fig. 5) (45). However, a PSMA-macropa conjugate, DUPA, showed no difference from $\left[{ }^{223} \mathrm{Ra}\right] \mathrm{RaCl}_{2}$ in subsequent biodistribution studies, highlighting the difficulty of developing stable chelates for $\mathrm{Ra}^{2+}$. DOTA and Kryptofix 2.2.2 (Merck) bind $\mathrm{Ra}^{2+}$ as well, evidenced by competition extraction experiments against calix[4]arene tetraacetate (46), but the stability of molecules. On the clinical front, ${ }^{225}$ Ac-DOTA bioconjugates of ${ }^{225}$ Ac-PSMA617, ${ }^{225}$ Ac-DOTATOC, and ${ }^{225}$ Ac-DOTA-HuM195 (8) have been evaluated. On the preclinical front, ${ }^{225}$ Ac-DOTATOC (49,50), -F3 (51), -c(RDGyK) (52), -MC1RL (53), -HuM195 (48), -J591 (anti-PSMA) (48), -B4 (anti-CD19) (48), and -trastuzumab (54) are all reported. It is noteworthy that unexpected high liver or spleen uptake observed in some studies may not be related to the in vivo stability of ${ }^{225} \mathrm{Ac}$-DOTA but rather to radiolysis (55), necessitating further study.

Large macrocyclic chelates have been used to ease the steric constraints for large metal ions and to increase the coordination number. 18-membered macrocycles with 6 donor atoms $(N$ or $O$ ) have been extensively studied. Macropa showed high specificity toward $\mathrm{Ac}^{3+}$ (56). It has been used to label PSMA-targeted RPS070 (56) and RPS074 (57) and showed good in vivo stability, effective tumor uptake, and therapy efficacy. Crown, another emerging chelate with structural similarity to DOTA, showed high labeling yields with $\mathrm{Ac}^{3+}$ at low concentrations $(55,58)$. It was conjugated to an $\alpha \mathrm{MSH}$ peptide targeting melanocortin 1 receptor and showed high tumor uptake and very low uptake in normal tissues and organs (55). HEHA, one of the first chelates developed specifically for $\mathrm{Ac}^{3+}$, showed promise in early studies $(59,60)$, but a conjugate with $\mathrm{mAb}-$ $\mathrm{B} 201 \mathrm{~B}$ slowly released free $\mathrm{Ac}^{3+}$ from the targeting organ (lungs) (61). Other macrocyclic chelates, such as PEPA (59), TETPA (62), TETA (62), DOTP (63), and macropid (Macrobid; Allergan Pharmaceuticals International Ltd.) (64), suffer either low labeling yield or

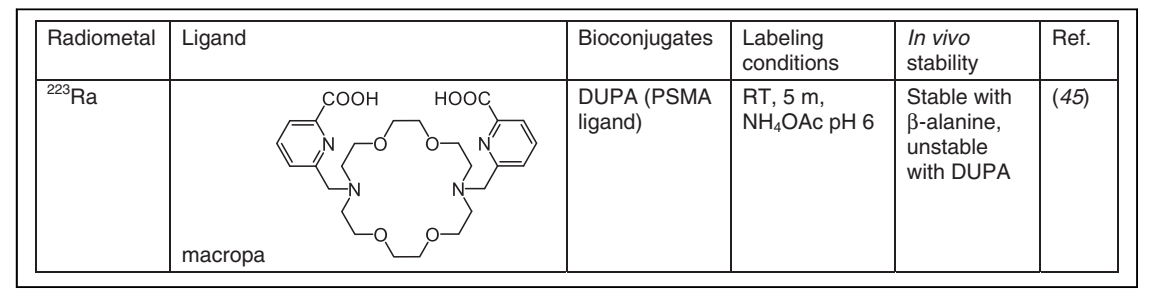

FIGURE 5. Chelators for ${ }^{223} \mathrm{Ra}$. RT = room temperature. 


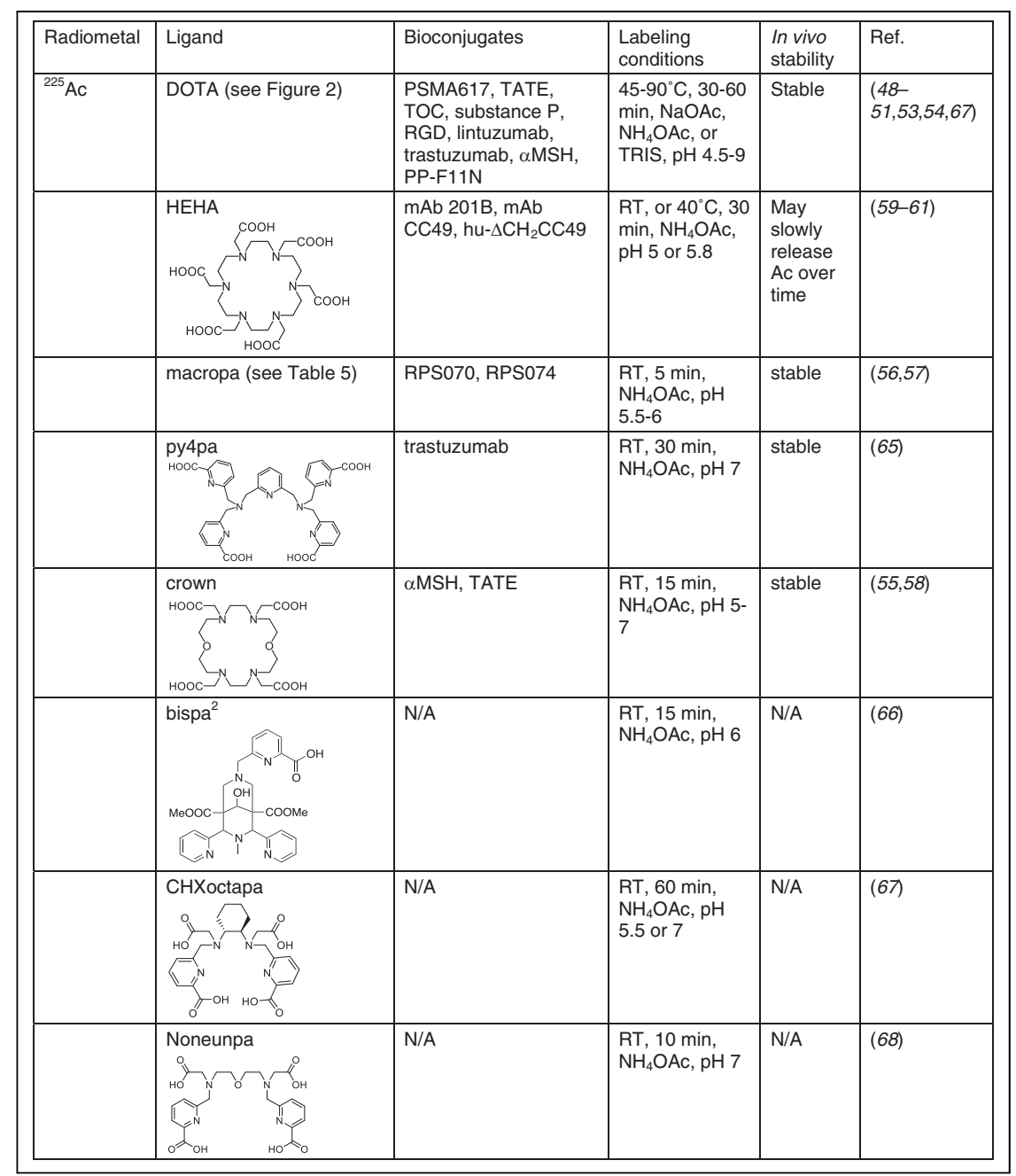

FIGURE 6. Chelators for ${ }^{225} \mathrm{Ac} . \mathrm{N} / \mathrm{A}=$ not applicable; $\mathrm{RT}=$ room temperature. penta(methylene phosphonic acid) (DTPMP) were evaluated in addition to the macrocyclic ligand (DOTMP) for this purpose $(69,70)$. In animal studies, all 3 complexes exhibited enhanced bone uptake compared with free $\left[{ }^{227} \mathrm{Th}\right] \mathrm{Th}^{4+}$, indicating that the phosphonate groups can facilitate bone targeting of this radionuclide and that these chelators form stable in vivo complexes with $\mathrm{Th}^{4+}$.

On the basis of its success with many other radiometals, the bifunctional analog of DOTA was studied to chelate ${ }^{227} \mathrm{Th}$. Early coordination chemistry studies, as well as more recent solid-state structural studies of Th-DOTA complexes (71-73) indicate that they should be stable in aqueous solution (Fig. 7). The most common process involves a low-yielding 2-step reaction; ${ }^{227} \mathrm{Th}$ is initially radiolabeled with bifunctional DOTA-NCS at an elevated temperature and then is conjugated to an antibody (74,75). A single-step radiolabeling reaction with a trastuzumab conjugated to DOTA required very long $(2 \mathrm{~d})$ reaction times (76). Despite the poor radiolabeling kinetics, the Th-DOTA complex retains good stability in vivo (75), enabling its use for various TAT applications.

Alternative chelators such as the picolinic acid "pa" chelators octapa, neunpa$p$-Bn- $\mathrm{NO}_{2}$, pypa, and py4pa were investigated for their ability to complex ${ }^{277} \mathrm{Th}$ (77). Among those 4 chelates, py 4 pa gave a high radiochemical yield ( $87 \%$ in $2.5 \mathrm{~h}$ ), and the complex remained intact in phos- poor in vivo stability, indicating that increasing ring size or adding more donor atoms may not always work.

Acyclic chelates with picolinic acid moieties have shown significant promise as $\mathrm{Ac}^{3+}$ chelates as well. Py4pa demonstrated a high Ac labeling yield at low chelate concentrations (65). The biodistribution of ${ }^{225}$ Ac-py4pa-trastuzumab showed effective tumor accumulation and relatively low liver uptake. Bispa ${ }^{2}$, CHXoctapa, and noneunpa all showed an excellent labeling yield at low chelate concentrations $(66-68)$. Those chelates can coordinate ${ }^{111}$ In as well, giving the advantage of potential theranostic pairs.

Overall, new chelators such as macropa, crown, and py4pa are highly promising because of the improved radiochemical yield, specific activity, and mild labeling conditions. One important area to address is whether the new chelators are capable of binding with an easily accessible imaging isotope, such as ${ }^{68} \mathrm{Ga}$ (imaging is essential for clinical translation of ${ }^{225}$ Ac-DOTA radiopharmaceuticals). For the chelators with a demonstrated ability to bind with an imaging isotope ( $\mathrm{Bispa}^{2}, \mathrm{CHXoctapa}$, noneunpa), in vivo studies are necessary to assess the stability and applications.

\section{${ }^{226 / 227}$ Th}

Early studies of ${ }^{227} \mathrm{Th}$ chelation used polyphosphonate-based chelates to target bone. Acyclic chelators ethylenediamine tetra(methylene phosphonic acid) (EDTMP) and diethylenetriamine phate-buffered saline solution for over 2 weeks. In view of these promising results, py4pa was investigated for chelating the shorter-lived ${ }^{226} \mathrm{Th}$ (77). Microwave irradiation afforded the radiolabeled complex in high yield, marking the first occasion of complexation of the ${ }^{226} \mathrm{Th}$ radionuclide.

Given the oxophilic nature of the $\mathrm{Th}^{4+}$ ion, the use of oxygen-rich chelating agents for these radionuclides is a promising approach. An octadentate hydroxypyridonate-based chelator bearing 4 bidentate 3-hydroxy- $N$-methyl-2-pyridinones (Me-3,2-HOPO) was validated to be an effective chelator for ${ }^{227} \mathrm{Th}(78)$. This ligand quantitatively incorporated ${ }^{227} \mathrm{Th}$ after $30 \mathrm{~min}$ at ambient temperature, marking a significant enhancement over the elevated temperatures required for DOTA; the resulting ${ }^{227} \mathrm{Th}$ complex was stable in vivo, as reflected by a lack of bone uptake. This chelator enabled several tumortargeting constructs to demonstrate the in vivo therapeutic potential of TAT with ${ }^{227} \mathrm{Th}$ (79-81). Detailed analytic studies on $\mathrm{Th}^{4+}$ chelation with this ligand revealed that it possesses a large ( $>20$ orders of magnitude) thermodynamic selectivity for +4 over +3 ions (82). This large selectivity for +4 ions may explain the high stability of its $\mathrm{Th}^{4+}$ complex in vivo, as biologically common +3 ions such as $\mathrm{Fe}^{3+}$ cannot effectively displace the actinide. The status of the Me-3,2-HOPO chelate as the current gold standard for ${ }^{227} \mathrm{Th}$ chelation has inspired additional 


\begin{tabular}{|c|c|c|c|c|c|}
\hline Radiometal & Ligand & Bioconjugates & $\begin{array}{l}\text { Labeling } \\
\text { conditions }\end{array}$ & $\begin{array}{l}\text { In vivo } \\
\text { stability }\end{array}$ & Ref. \\
\hline \multirow[t]{4}{*}{${ }^{226 / 227} \mathrm{Th}$} & DOTA (see Figure 2) & $\begin{array}{l}\text { Rituximab, } \\
\text { trastuzumab }\end{array}$ & $\begin{array}{l}55-60^{\circ} \mathrm{C}, 30 \mathrm{~m}, \\
\mathrm{NMe}_{4} \mathrm{OAc}, \mathrm{pH} 5.5\end{array}$ & Stable & $(71-76)$ \\
\hline & $\mathrm{Me}-3,2-\mathrm{HOPO}$ & $\begin{array}{l}\text { Anti-CD33 } \\
\text { mAb, anti- } \\
\text { CD70 mAB, } \\
\text { mesothelin } \\
\text { targeted mAb. }\end{array}$ & $\begin{array}{l}\text { RT, } 30 \mathrm{~m} \text {, citrate } \\
\text { pH } 5.5\end{array}$ & Stable & $(78-82)$ \\
\hline & py4pa (see Table 6) & N/A & $\begin{array}{l}\mathrm{RT}, 2.5 \mathrm{~h} \text {, citrate } \\
\mathrm{pH} 5-5.5\end{array}$ & N/A & (77) \\
\hline & macrocyclic tetrapthali & N/A & $\begin{array}{l}\text { Reflux in } \mathrm{MeOH}, \\
3 \mathrm{~h}\end{array}$ & $\mathrm{~N} / \mathrm{A}$ & (83) \\
\hline
\end{tabular}

FIGURE 7. Chelators for ${ }^{226 / 227} \mathrm{Th} . \mathrm{N} / \mathrm{A}=$ not applicable; $\mathrm{RT}=$ room temperature.

$\mathrm{U}^{4+}$ in water (90). HEHA, investigated for ${ }^{225} \mathrm{Ac}$, also forms a stereochemically rigid and therefore potentially inert complex with $\mathrm{U}^{4+}(91)$. Thus, these results suggest that targeting the chelation of $\mathrm{U}^{4+}$, perhaps by modulating the redox conditions of the radiochemical isolation and separation of ${ }^{230} \mathrm{U}$, may provide an alternative effective means for delivering this radionuclide to tumor cells. Although ${ }^{230} \mathrm{U}$ has been proposed to be a promising candidate for TAT, there are currently no in vivo or in vitro studies that have demonstrated its efficacy for eliminating malignant cells. As such, chelation efforts for this radionuclide are somewhat underdeveloped; however, the principles of $U$ chelation that have been established for other applications are likely pertinent to future ${ }^{230} \mathrm{U}$ TAT applications.

\section{CHALLENGES AND OPPORTUNITIES}

studies on ligands of this type. A recently reported macrocyclic tetrapthalimide ligand was found to have the highest thermodynamic affinity for $\mathrm{Th}^{4+}$ discovered to date $\left(\log \mathrm{K}=10^{54}\right)$, representing a promising candidate for ${ }^{227} \mathrm{Th}$ TAT (83).

Overall, oxygen-rich chelators are effective for stabilizing the hard, oxophilic $\mathrm{Th}^{4+}$ ion in vivo. The HOPO-containing ligands are among the most promising candidates for use with Th-based TAT, but these chelators suffer from challenging chemical syntheses. The development of more readily accessible polydentate oxygen-rich chelators will meet an important need for advancing Th-based TAT.

\section{${ }^{230} \mathrm{U}$}

The chemically hard and oxophilic nature of the $\left[\mathrm{UO}_{2}\right]^{2+}$ ion dictates anionic oxygen-donor ligands. These conclusions are supported by many decades of $\left[\mathrm{UO}_{2}\right]^{2+}$ coordination chemistry $(84)$. Nevertheless, there have been surprisingly few studies to develop chelators specifically for ${ }^{230} \mathrm{U}$ TAT. The lack of ${ }^{230} \mathrm{U}$ TAT studies is a consequence of the limited availability of the radionuclide and narrow knowledge of its potential importance in nuclear medicine. Researchers have investigated the interactions of the $\left[\mathrm{UO}_{2}\right]^{2+}$ ion with the human serum proteins transferrin and albumin, in addition to other small molecules, such as carbonate, that are present in blood in order to assess the needed efficacy of a potential ${ }^{230} \mathrm{U}$ chelator (85). An effective chelator for this radionuclide was predicted to have a stability constant in excess of $10^{19}(85)$; there are few chelators with such a high stability constant for $\left[\mathrm{UO}_{2}\right]^{2+}$. For example, calixarene ligands were found to form unstable complexes with $\left[{ }^{238} \mathrm{UO}_{2}\right]^{2+}$ that dissociated in serum (86). Given the expansive literature and efforts to develop $\mathrm{U}$ decorporation agents, however, it is likely that there are promising candidates for ${ }^{230} \mathrm{U}$ chelation extant. For example, the deferoxamine complex of $\mathrm{UO}_{2}{ }^{2+}$ has a stability constant within this range (87), as does a class of hexadentate equatorial-spanning terephthalamide(bis-hydroxypyridinone) ligands (88), suggesting that these chelators may be useful for ${ }^{230} \mathrm{U}$ TAT applications.

Although the $\left[\mathrm{UO}_{2}\right]^{2+}$ ion predominates in aqueous solution, $\mathrm{U}^{4+}$ is also found. DOTA complexes of $\mathrm{U}^{4+}$ are well characterized and are stable to oxidation in aqueous solution $(72,73,89)$. HOPO-based ligands can facilitate the reduction of $\left[\mathrm{UO}_{2}\right]^{2+}$ to
Lutathera, as the first regulatory body-approved (United States and European Union) compound for peptide receptor radionuclide therapy, has stimulated substantial interest in targeted radiotherapy, particularly to treat patients with metastatic disease. $\alpha$-emitters are highly promising for radiotherapeutic agents, illustrating viability in the treatment of a wide range of malignancies. This surge of interest, particularly in the actinides, however, has outpaced the understanding of the chemistry of each individual element; this understanding remains poorly developed because of the limited supply of the elements and the usually intense radioactivity of all isotopes. Any future coordination chemistry research will depend on reliable availability of $\alpha$-emitting radionuclides. New production methods coming on-line now mean that supply is approaching levels capable of supporting preclinical as well as clinical studies on a routine basis, and further research into the coordination chemistry of these isotopes is now possible. With half-lives that range from around $1 \mathrm{~h}\left({ }^{212,213} \mathrm{Bi}\right)$ to weeks $\left({ }^{227} \mathrm{Th}\right)$, coupled with the radiologic and biologic considerations needed, the challenges in chelating these metals are considerable.

An important step to advance novel chelates is to find a readily available imaging isotope for those specific chelates for patient stratification and treatment monitoring, which can be challenging because relevant $\alpha$-emitters typically maintain significantly different chemical properties. The challenge can be addressed either by designing and testing chelates that can accommodate both (68) or by developing imaging radioisotopes, such as ${ }^{134} \mathrm{Ce} /{ }^{134} \mathrm{La}(92)$, that are closer in nature to emerging actinide-based $\alpha$-emitters.

One of the major impediments to using $\alpha$-emitting radionuclides has been the need for improved chelators or labeling methods to ensure that they remain stable in vivo in order to deliver their payload to the target tissue and minimize the dose that can arise because of dissociation and off-target tissue localization.

Metal-ligand bonding in actinide complexes has been thought to be driven primarily by electrostatic interactions and steric constraints, with limited orbital interaction. Early efforts show that one can match isotopes to chelators, but actinides show significantly more covalency than lanthanides (68). Further studies of fundamental actinide coordination and organometallic chemistry will enlighten more specific chelate designs. 
$\alpha$-recoil will cause the progenies to leave the chelates and free the daughters, which may carry significant or even most of the energy, as in the case of ${ }^{225}$ Ac decay. Fast pharmacokinetics and sufficient internalization are highly desirable to limit off-target toxicity and maximize the tumor dose. Other methods to mitigate the risk include encapsulating in nanoparticles or localized administration (10).

The tumor microenvironment includes, as 3 major cell types, immune, stromal, and vascular cells, and the potential to target each will become more exact using unique combinations of elements/isotopes with chelators and more specific targeting vectors. The incorporation of $\alpha$-emitters into nanomaterials (with or without chelation) presents another front of interest to TAT.

In summary, a focus on new tightly binding, selective chelating ligands that can yield high specific activity radiopharmaceuticals will soon be necessary. Reproducibly versatile and subsequently translatable chelation chemistry is required. Other areas important for realizing the full potential of $\alpha$-emitting radiopharmaceuticals include, but are not limited to: modular and automated (smart) technologies for high-level synthesis, kit-formulation for ease of preparation, as well as a better understanding of the biology of daughter isotopes released via recoil, as this could be a limiting factor in the efficacy of emerging radiopharmaceuticals due to their toxicity. All of these challenges represent opportunities for research in the expanding field of TAT.

\section{DISCLOSURE}

TRIUMF receives funding via a contribution agreement with the National Research Council of Canada. Justin Wilson receives support through the U.S. National Institutes of Health under awards R21EB027282 and R01EB029259. Chris Orvig has received many years of support from NSERC and CIHR. Paul Schaffer is a consultant for ARTMS, Inc., as chief technology officer. Justin Wilson holds equity in Ratio Therapeutics, which has licensed macropa for chelation of $\alpha$-emitters. No other potential conflict of interest relevant to this article was reported.

\section{REFERENCES}

1. Gudkov SV, Shilyagina N, Vodeneev V, Zvyagin A. Targeted radionuclide therapy of human tumors. Int J Mol Sci. 2015;17:33.

2. Pouget JP, Navarro-Teulon I, Bardiès M, et al. Clinical radioimmunotherapy: the role of radiobiology. Nat Rev Clin Oncol. 2011;8:720-734.

3. Morgenstern A, Apostolidis C, Kratochwil C, Sathekge M, Krolicki L, Bruchertseifer F. An overview of targeted alpha therapy with ${ }^{225}$ actinium and ${ }^{213}$ bismuth. Curr Radiopharm. 2018;11:200-208.

4. Scheinberg DA, McDevitt MR. Actinium-225 in targeted alpha-particle therapeutic applications. Curr Radiopharm. 2011;4:306-320.

5. Sgouros G, Roeske JC, McDevitt MR, et al. MIRD pamphlet no. 22 (abridged): radiobiology and dosimetry of $\alpha$-particle emitters for targeted radionuclide therapy. J Nucl Med. 2010;51:311-328.

6. Wulbrand C, Seidl C, Gaertner FC, et al. Alpha-particle emitting ${ }^{213}$ Bi-anti-EGFR immunoconjugates eradicate tumor cells independent of oxygenation. PLoS One. 2013;8:e64730.

7. Staudacher AH, Liapis V, Brown MP. Therapeutic targeting of tumor hypoxia and necrosis with antibody $\alpha$-radioconjugates. Antib Ther. 2018;1:55-63.

8. Morgenstern A, Apostolidis C, Bruchertseifer F. Supply and clinical application of actinium-225 and bismuth-213. Semin Nucl Med. 2020;50:119-123.

9. Kratochwil C, Bruchertseifer F, Giesel FL, et al. ${ }^{225}$ Ac-PSMA-617 for PSMAtargeted $\alpha$-radiation therapy of metastatic castration-resistant prostate cancer. J Nucl Med. 2016;57:1941-1944.

10. de Kruijff RM, Wolterbeek HT, Denkova AG. A critical review of alpha radionuclide therapy: how to deal with recoiling daughters? Pharmaceuticals (Basel). 2015;8:321-336.

11. Chen H, Shi R, Ow H. Predicting stability constants for terbium(III) complexes with dipicolinic acid and 4-substituted dipicolinic acid analogues using density functional theory. ACS Omega. 2019;4:20665-20671.
12. Natrajan LS, Khoabane NM, Dadds BL, et al. Probing the structure, conformation, and stereochemical exchange in a family of lanthanide complexes derived from tetrapyridyl-appended cyclen. Inorg Chem. 2010;49:7700-7709.

13. Müller C, Vermeulen C, Köster U, et al. Alpha-PET with terbium-149: evidence and perspectives for radiotheragnostics. EJNMMI Radiopharm Chem. 2017;1:5.

14. Müller C, Reber J, Haller S, et al. Folate receptor targeted alpha-therapy using terbium-149. Pharmaceuticals (Basel). 2014;7:353-365.

15. Beyer GJ, Miederer M, Vranješ-Durić S, et al. Targeted alpha therapy in vivo: direct evidence for single cancer cell kill using ${ }^{149}$ Tb-rituximab. Eur J Nucl Med Mol Imaging. 2004;31:547-554.

16. Wilbur DS. Chemical and radiochemical considerations in radiolabeling with $\alpha$-emitting radionuclides. Curr Radiopharm. 2012;4:214-247.

17. Wilbur D. $\left[{ }^{211} \mathrm{At}\right]$ astatine-labeled compound stability: issues with released $\left[{ }^{211} \mathrm{At}\right]$ astatide and development of labeling reagents to increase stability. Curr Radiopharm. 2008;1:144-176.

18. Guérard F, Gestin JF, Brechbiel MW. Production of $\left[{ }^{211} \mathrm{At}\right]$-astatinated radiopharmaceuticals and applications in targeted $\alpha$-particle therapy. Cancer Biother Radiopharm. 2013;28:1-20.

19. Pruszyński M, Łyczko M, Bilewicz A, Zalutsky MR. Stability and in vivo behavior of Rh[16aneS4-diol] ${ }^{211}$ At complex: a potential precursor for astatine radiopharmaceuticals. Nucl Med Biol. 2015;42:439-445.

20. Andersson H, Cederkrantz E, Bäck T, et al. Intraperitoneal $\alpha$-particle radioimmunotherapy of ovarian cancer patients: pharmacokinetics and dosimetry of ${ }^{211}$ AtMX35 F(ab')2 - a phase I study. J Nucl Med. 2009;50:1153-1160.

21. Zalutsky MR, Reardon DA, Akabani G, et al. Clinical experience with $\alpha$-particleemitting ${ }^{211}$ At: treatment of recurrent brain tumor patients with ${ }^{211}$ At-labeled chimeric antitenascin monoclonal antibody 81C6. J Nucl Med. 2008;49:30-38.

22. Lindegren S, Frost S, Bäck T, Haglund E, Elgqvist J, Jensen H. Direct procedure for the production of ${ }^{211}$ At-labeled antibodies with an $\varepsilon$-lysyl-3-(trimethylstannyl)benzamide immunoconjugate. J Nucl Med. 2008;49:1537-1545.

23. Mansfield A, Lee H, Verdone J, et al. PARP-1 targeted alpha-emitting radiotherapeutics: an examination of potential toxicity [abstract]. J Med Imaging Radiat Sci. 2019;50(suppl 1):S29-S30.

24. Makvandi M, Lee H, Puentes LN, et al. Targeting PARP-1 with alpha-particles is potently cytotoxic to human neuroblastoma in preclinical models. Mol Cancer Ther. 2019;18:1195-1204.

25. Berdal M, Gouard S, Eychenne R, et al. Investigation on the reactivity of nucleophilic radiohalogens with arylboronic acids in water: access to an efficient singlestep method for the radioiodination and astatination of antibodies. Chem Sci. 2020; 12:1458-1468.

26. Majkowska-Pilip A, Gaweda W, Żelechowska-Matysiak K, Wawrowicz K, Bilewicz A. Nanoparticles in targeted alpha therapy. Nanomaterials (Basel). 2020;10:1-25.

27. Šimeček J, Hermann P, Seidl C, et al. Efficient formation of inert Bi-213 chelates by tetraphosphorus acid analogues of DOTA: towards improved alpha-therapeutics. EJNMMI Res. 2018;8:78.

28. Wilson JJ, Ferrier M, Radchenko V, et al. Evaluation of nitrogen-rich macrocyclic ligands for the chelation of therapeutic bismuth radioisotopes. Nucl Med Biol. 2015;42:428-438.

29. Kang CS, Song HA, Milenic DE, Baidoo KE, Brechbiel MW, Chong HS. Preclinical evaluation of NETA-based bifunctional ligand for radioimmunotherapy applications using ${ }^{212} \mathrm{Bi}$ and ${ }^{213} \mathrm{Bi}$ : radiolabeling, serum stability, and biodistribution and tumor uptake studies. Nucl Med Biol. 2013;40:600-605.

30. Song HA, Kang CS, Baidoo KE, et al. Efficient bifunctional decadentate ligand 3p-C-DEPA for targeted $\alpha$-radioimmunotherapy applications. Bioconjug Chem. 2011;22:1128-1135.

31. Slikkerveer A, Noach LA, Tytgat GNJ, Van Der Voet GB, De Wolff FA. Comparison of enhanced elimination of bismuth in humans after treatment with meso-2,3dimercaptosuccinic acid and D,L-2,3-dimercaptopropane-1-sulfonic acid. In: Analyst. Vol 123. The Royal Society of Chemistry; 1998:91-92.

32. Pippin CG, McMurry TJ, Brechbiel MW, et al. Lead(II) complexes of 1,4,7,10-tetraazacyclododecane- $\mathrm{N}, \mathrm{N}^{\prime}, \mathrm{N}^{\prime}, \mathrm{N}^{\prime \prime \prime}$-tetraacetate: solution chemistry and application to tumor localization with ${ }^{203} \mathrm{~Pb}$ labeled monoclonal antibodies. Inorg Chim Acta. 1995;239:43-51.

33. Yong K, Brechbiel MW. Towards translation of ${ }^{212} \mathrm{~Pb}$ as a clinical therapeutic: getting the lead in! Dalton Trans. 2011;40:6068-6076.

34. Su FM, Beaumier P, Axworthy D, Atcher R, Fritzberg A. Pretargeted radioimmunotherapy in tumored mice using an in vivo ${ }^{212} \mathrm{~Pb} /{ }^{212} \mathrm{Bi}$ generator. Nucl Med Biol. 2005;32:741-747.

35. Miao Y, Hylarides M, Fisher DR, et al. Melanoma therapy via peptide-targeted $\alpha$-radiation. Clin Cancer Res. 2005;11:5616-5621.

36. Ruble G, Chuanchu W, Squire RA, Gansow OA, Strand M. The use of ${ }^{212} \mathrm{~Pb}-$ labeled monoclonal antibody in the treatment of murine erythroleukemia. Int $J$ Radiat Oncol Biol Phys. 1996;34:609-616.

37. Chappell LL, Dadachova E, Milenic DE, Garmestani K, Wu C, Brechbiel MW. Synthesis, characterization, and evaluation of a novel bifunctional chelating agent for the lead isotopes ${ }^{203} \mathrm{~Pb}$ and ${ }^{212} \mathrm{~Pb}$. Nucl Med Biol. 2000;27:93-100. 
38. Tan Z, Chen P, Schneider N, et al. Significant systemic therapeutic effects of highLET immunoradiation by ${ }^{212} \mathrm{~Pb}$-trastuzumab against prostatic tumors of androgenindependent human prostate cancer in mice. Int J Oncol. 2012;40:1881-1888.

39. Meredith RF, Torgue JJ, Rozgaja TA, et al. Safety and outcome measures of firstin-human intraperitoneal $\alpha$ radioimmunotherapy with ${ }^{212} \mathrm{~Pb}$-TCMC-trastuzumab. Am J Clin Oncol. 2018;41:716-721.

40. Banerjee SR, Minn I, Kumar V, et al. Preclinical evaluation of ${ }^{203 / 212} \mathrm{~Pb}$-labeled low-molecular-weight compounds for targeted radiopharmaceutical therapy of prostate cancer. J Nucl Med. 2020;61:80-88.

41. Stenberg VY, Larsen RH, Ma L-W, et al. Evaluation of the PSMA-binding ligand ${ }^{212} \mathrm{~Pb}-\mathrm{NG} 001$ in multicellular tumour spheroid and mouse models of prostate cancer. Int J Mol Sci. 2021;22:4815.

42. Kasten BB, Arend RC, Katre AA, et al. B7-H3-targeted ${ }^{212} \mathrm{~Pb}$ radioimmunotherapy of ovarian cancer in preclinical models. Nucl Med Biol. 2017;47:23-30.

43. McNeil BL, Robertson AKH, Fu W, et al. Production, purification, and radiolabeling of the ${ }^{203} \mathrm{~Pb} /{ }^{212} \mathrm{~Pb}$ theranostic pair. EJNMMI Radiopharm Chem. 2021;6:6.

44. Bauer D, Blumberg M, Köckerling M, Mamat C. A comparative evaluation of calix[4]arene-1,3-crown-6 as a ligand for selected divalent cations of radiopharmaceutical interest. RSC Advances. 2019;9:32357-32366.

45. Abou DS, Thiele NA, Gutsche NT, et al. Towards the stable chelation of radium for biomedical applications with an 18-membered macrocyclic ligand. Chem Sci. $2021 ; 12: 3733-3742$.

46. Henriksen G, Hoff P, Larsen RH. Evaluation of potential chelating agents for radium. Appl Radiat Isot. 2002;56:667-671.

47. Maguire WF, McDevitt MR, Smith-Jones PM, Scheinberg DA. Efficient 1-step radiolabeling of monoclonal antibodies to high specific activity with ${ }^{225} \mathrm{Ac}$ for a-particle radioimmunotherapy of cancer. J Nucl Med. 2014;55:1492-1498.

48. McDevitt MR, Ma D, Lai LT, et al. Tumor therapy with targeted atomic nanogenerators. Science. 2001;294:1537-1540.

49. Miederer M, Henriksen G, Alke A, et al. Preclinical evaluation of the $\alpha$-particle generator nuclide ${ }^{225} \mathrm{Ac}$ for somatostatin receptor radiotherapy of neuroendocrine tumors. Clin Cancer Res. 2008;14:3555-3561.

50. Graf F, Fahrer J, Maus S, et al. DNA double strand breaks as predictor of efficacy of the alpha-particle emitter Ac-225 and the electron emitter Lu-177 for somatostatin receptor targeted radiotherapy. PLoS One. 2014;9:e88239.

51. Essler M, Gärtner FC, Neff F, et al. Therapeutic efficacy and toxicity of ${ }^{225}$ Aclabelled vs. ${ }^{213} \mathrm{Bi}$-labelled tumour-homing peptides in a preclinical mouse model of peritoneal carcinomatosis. Eur J Nucl Med Mol Imaging. 2012;39:602-612.

52. Zhang C, Zhang Z, Lin KS, et al. Preclinical melanoma imaging with ${ }^{68} \mathrm{Ga}$-labeled $\alpha$-melanocyte-stimulating hormone derivatives using PET. Theranostics. 2017;7: 805-813.

53. Tafreshi NK, Tichacek CJ, Pandya DN, et al. Melanocortin 1 receptor-targeted $\alpha$-particle therapy for metastatic uveal melanoma. J Nucl Med. 2019;60:1124-1133.

54. Ballangrud ÅM, Yang WH, Palm S, et al. Alpha-particle emitting atomic generator actinium-225)-labeled trastuzumab (Herceptin) targeting of breast cancer spheroids: efficacy versus HER2/neu expression. Clin Cancer Res. 2004;10:4489-4497.

55. Yang H, Zhang C, Yuan Z, et al. Synthesis and evaluation of a new macrocyclic actinium-225 chelator, quality control and in vivo evaluation of ${ }^{225}$ Ac-crown$\alpha$ MSH peptide. Chemistry. 2020;26:11435-11440.

56. Thiele NA, Brown V, Kelly JM, et al. An eighteen-membered macrocyclic ligand for actinium-225 targeted alpha therapy. Angew Chem Int Ed Engl. 2017;56: $14712-14717$.

57. Kelly JM, Amor-Coarasa A, Ponnala S, et al. A single dose of ${ }^{225}$ Ac-RPS-074 induces a complete tumor response in an LNCaP xenograft model. $J$ Nucl Med. 2019;60:649-655.

58. Yang H, Gao F, Yuan Z, et al. A novel actinium bifunctional chelator Crown and biodistribution of Ac-225-Crown-TATE [abstract]. J Nucl Med. 2020;61(suppl 1): 1235 .

59. Deal KA, Davis IA, Mirzadeh S, Kennel SJ, Brechbiel MW. Improved in vivo stability of actinium-225 macrocyclic complexes. J Med Chem. 1999;42:2988-2992.

60. Kennel SJ, Brechbiel MW, Milenic DE, Schlom J, Mirzadeh S. Actinium-225 conjugates of MAb CC49 and humanized $\triangle \mathrm{CH} 2 \mathrm{CC} 49$. Cancer Biother Radiopharm. 2002;17:219-231.

61. Kennel SJ, Chappell LL, Dadachova K, et al. Evaluation of ${ }^{225}$ Ac for vascular targeted radioimmunotherapy of lung tumors. Cancer Biother Radiopharm. 2000;15: 235-244.

62. McDevitt MR, Ma D, Simon J, Frank RK, Scheinberg DA. Design and synthesis of ${ }^{225}$ Ac radioimmunopharmaceuticals. Appl Radiat Isot. 2002;57:841-847.

63. Stein BW, Morgenstern A, Batista ER, et al. Advancing chelation chemistry for actinium and other +3 f-elements, Am, Cm, and La. J Am Chem Soc. 2019;141: 19404-19414.

64. Thiele NA, Wilson JJ. Actinium-225 for targeted $\alpha$ therapy: coordination chemistry and current chelation approaches. In: Cancer Biotherapy and Radiopharmaceuticals. Vol 33. Mary Ann Liebert Inc.; 2018:336-348.
65. Li L, Rousseau J, Jaraquemada-Peláez M de G, et al. ${ }^{225}$ Ac-H 4 py4pa for targeted alpha therapy. Bioconjug Chem. 2021;32:1348-1363.

66. Comba P, Jermilova U, Orvig C, et al. Octadentate picolinic acid-based bispidine ligand for radiometal ions. Chemistry. 2017;23:15945-15956.

67. Ramogida CF, Robertson AKH, Jermilova U, et al. Evaluation of polydentate picolinic acid chelating ligands and an $\alpha$-melanocyte-stimulating hormone derivative for targeted alpha therapy using ISOL-produced ${ }^{225}$ Ac. EJNMMI Radiopharm Chem. 2019;4:21.

68. Wharton L, Kurakina E, Radchenko V, Schaffer P, Orvig C. Chemical promiscuity of non-macrocyclic multidentate chelating ligands for radiometal ions: H4neunpaNH2 vs H4noneunpa. Inorg Chem. 2021;60:4076-4092.

69. Henriksen G, Bruland ØS, Larsen RH. Thorium and actinium polyphosphonate compounds as bone-seeking alpha particle-emitting agents. Anticancer Res. 2004; 24:101-105.

70. Washiyama K, Amano R, Sasaki J, et al. ${ }^{227}$ Th-EDTMP: a potential therapeutic agent for bone metastasis. Nucl Med Biol. 2004;31:901-908.

71. Jacques V, Desreux JF. Kinetically and thermodynamically stable isomers of thorium chelates of polyaza polycarboxylic macrocycles. J Alloys Compd. 1994;213:286-289.

72. Tamain C, Dumas T, Hennig C, Guilbaud P. Coordination of tetravalent actinides $(\mathrm{An}=\mathrm{ThIV}, \mathrm{UIV}, \mathrm{NpIV}, \mathrm{PuIV})$ with DOTA: from dimers to hexamers. Chemistry. 2017;23:6864-6875.

73. Kent GT, Wu G, Hayton TW. Synthesis and crystallographic characterization of the tetravalent actinide-DOTA complexes $[\operatorname{AnIV}(\kappa 8$-DOTA $)(\mathrm{DMSO})](\mathrm{An}=\mathrm{Th}$, U). Inorg Chem. 2019;58:8253-8256.

74. Dahle J, Borrebæk J, Melhus KB, et al. Initial evaluation of ${ }^{227} \mathrm{Th}$ - $p$-benzylDOTA-rituximab for low-dose rate $\alpha$-particle radioimmunotherapy. $\mathrm{Nucl} \mathrm{Med}$ Biol. 2006;33:271-279.

75. Larsen RH, Borrebaek J, Dahle J, et al. Preparation of $\mathrm{TH}^{227}$-labeled radioimmunoconjugates, assessment of serum stability and antigen binding ability. Cancer Biother Radiopharm. 2007;22:431-437.

76. Heyerdahl H, Abbas N, Brevik EM, Mollatt C, Dahle J. Fractionated therapy of HER2-expressing breast and ovarian cancer xenografts in mice with targeted alpha emitting ${ }^{227}$ Th-DOTA-p-benzyl-trastuzumab. PLoS One. 2012;7:e42345.

77. Ferrier MG, Li Y, Chyan M-K, et al. Thorium chelators for targeted alpha therapy: rapid chelation of thorium-226. J Labelled Compd Radiopharm. 2020;63:502-516.

78. Ramdahl T, Bonge-Hansen HT, Ryan OB, et al. An efficient chelator for complexation of thorium-227. Bioorg Med Chem Lett. 2016;26:4318-4321.

79. Hagemann UB, Wickstroem $\mathrm{K}$, Wang E, et al. In vitro and in vivo efficacy of a novel CD33-targeted thorium-227 conjugate for the treatment of acute myeloid leukemia. Mol Cancer Ther. 2016;15:2422-2431.

80. Hagemann UB, Mihaylova D, Uran SR, et al. Targeted alpha therapy using a novel CD70 targeted thorium-227 conjugate in in vitro and in vivo models of renal cell carcinoma. Oncotarget. 2017;8:56311-56326.

81. Hagemann UB, Ellingsen C, Schuhmacher J, et al. Mesothelin-targeted thorium227 conjugate (MSLN-TTC): preclinical evaluation of a new targeted alpha therapy for mesothelin-positive cancers. Clin Cancer Res. 2019;25:4723-4734.

82. Deblonde GJP, Lohrey TD, Booth CH, et al. Solution thermodynamics and kinetics of metal complexation with a hydroxypyridinone chelator designed for thorium227 targeted alpha therapy. Inorg Chem. 2018;57:14337-14346.

83. Pham TA, Xu J, Raymond KN. A macrocyclic chelator with unprecedented Th4+ affinity. J Am Chem Soc. 2014;136:9106-9115.

84. Gorden AEV, Xu J, Raymond KN, Durbin P. Rational design of sequestering agents for plutonium and other actinides. Chem Rev. 2003;103:4207-4282.

85. Montavon G, Apostolidis C, Bruchertseifer F, Repinc U, Morgenstern A. Spectroscopic study of the interaction of U(VI) with transferrin and albumin for speciation of U(VI) under blood serum conditions. J Inorg Biochem. 2009;103:1609-1616.

86. Montavon G, Repinc U, Apostolidis C, Bruchertseifer F, Abbas K, Morgenstern A. Investigation of para-sulfonatocalix $[n]$ arenes $[n=6,8]$ as potential chelates for ${ }^{230}$ U. Dalton Trans. 2010;39:1366-1374.

87. Mullen L, Gong C, Czerwinski K. Complexation of uranium (VI) with the siderophore desferrioxamine B. J Radioanal Nucl Chem. 2007;273:683-688.

88. Szigethy G, Raymond KN. Hexadentate terephthalamide(bis-hydroxypyridinone) ligands for uranyl chelation: structural and thermodynamic consequences of ligand variation 1. J Am Chem Soc. 2011;133:7942-7956.

89. Dovrat G, Illy MC, Berthon C, et al. On the aqueous chemistry of the UIV-DOTA complex. Chemistry. 2020;26:3390-3403.

90. Carter KP, Smith KF, Tratnjek T, et al. Controlling the reduction of chelated uranyl to stable tetravalent uranium coordination complexes in aqueous solution. Inorg Chem. 2021;60:973-981.

91. Jacques V, Desreux JF. Complexation of thorium(IV) and uranium(IV) by a hexaacetic hexaaza macrocycle: kinetic and thermodynamic topomers of actinide chelates with a large cavity ligand. Inorg Chem. 1996;35:7205-7210.

92. Bailey TA, Mocko V, Shield KM, et al. Developing the ${ }^{134} \mathrm{Ce}$ and ${ }^{134} \mathrm{La}$ pair as companion positron emission tomography diagnostic isotopes for ${ }^{225} \mathrm{Ac}$ and ${ }^{227} \mathrm{Th}$ radiotherapeutics. Nat Chem. 2021;13:284-289. 